Int. J. Electrochem. Sci., 12 (2017) $9944-9957$

International Journal of

ELECTROCHEMICAL

SCIENCE

www.electrochemsci.org

\title{
Preparation and Anticorrosive Properties of Oligoaniline Modified Silica Coatings
}

\author{
Yuwei Ye ${ }^{1,2}$, Wei Liu ${ }^{1}$, Zhiyong Liu ${ }^{1}$, Haichao Zhao ${ }^{2 *}$, Liping Wang ${ }^{2 *}$ \\ ${ }^{1}$ Corrosion \& Protection Centre, University of Science \& Technology Beijing, Beijing 100083, China; \\ ${ }^{2}$ Key Laboratory of Marine Materials and Related Technology, Zhejiang Key Laboratory of Marine \\ Materials and Protective Technologies, Ningbo Institute of Materials Technology \& Engineering, \\ Chinese Academy of Sciences, Ningbo, 315201, China \\ *E-mail: zhaohaichao@nimte.ac.cn, wangliping@nimte.ac.cn
}

doi: 10.20964/2017.11.11

Received: 1 July 2017 / Accepted: 26 August 2017 / Published: 12 October 2017

Novel trianiline-containing sol-gel hybrid coatings were prepared by one-step electrodeposition technology on the surface of Q235 steel. The chemical component, microstructure of the as-prepared coatings were measured by FTIR, UV-vis, SEM. The effects of deposition time on the thickness, contact angle (CA) and surface roughness of coatings were investigated. The results showed that the modified silica coatings exhibited an excellent hydrophobic nature. By comparing with various deposition times $(100,300,500,700 \mathrm{~s})$ under the deposition potential of $-1.5 \mathrm{~V}$, the coating under the deposition time of $500 \mathrm{~s}$ presented the best anti-corrosion effectiveness for bare steel substrate in 3.5 wt.\% $\mathrm{NaCl}$ solution as verified by Tafel curves and electrochemical impedance spectroscopy (EIS).

Keywords: Oligoaniline; Sol-Gel coating; Electrodeposition; Corrosion resistance; Hydrophobicity

\section{$\underline{\text { FULL TEXT }}$}

(C) 2017 The Authors. Published by ESG (www.electrochemsci.org). This article is an open access article distributed under the terms and conditions of the Creative Commons Attribution license (http://creativecommons.org/licenses/by/4.0/). 